\title{
Incidence of latrogenic Lumbar Spinal Instability after Laminectomy, Discectomy or Facetectomy
}

\author{
Ahmed A. Hafez, Ahmed Hamdy Ashry, Ahmed Elsayed, Amr El Tayeb DiD, Mohamed Badran Abdel Salam EIShenawy \\ Department of Neurosurgery, Faculty of Medicine, Cairo University, Giza, Egypt
}

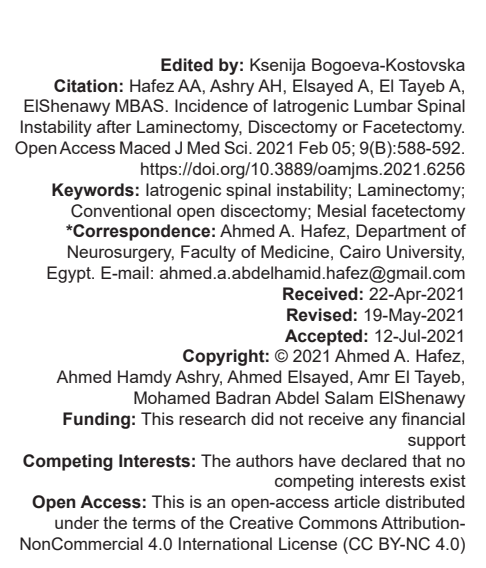

Introduction

Spinal stability is accomplished by dynamic interaction of many structural systems in the body. White and Panjabi proposed one definition of clinical instability as follows: "The loss of the ability of the spine to maintain its pattern of displacement under physiologic loads so that there is no initial or additional neurological deficit, no major deformity, and no incapacitating pain". latrogenic instability can occur after discectomy and laminectomy and due to adjacent segment degeneration [1].

Posterior complex (spinous process/ supraspinous ligament) integrity appears to play an important role in maintaining lumbar spine stability. The spinous process, supraspinous ligament, interspinous ligament, lamina, and ligamentum flavum are all removed during a laminectomy. This could cause the posterior complex to become unstable. Some studies suggest that this leads to iatrogenic instability manifested as adjacent segment degeneration [2].

When iatrogenic instability occurs, patient complains of axial low back pain or radicular pain. The solution in these cases includes observation and medical treatment (physical therapy and epidural steroid injections) or operative intervention if nonoperative measures fail. Lumbar fusion, with or without revision decompression, is the most common surgical intervention [3].

Lumbar disc prolapse is a common occurrence in a variety of patient populations, there are several techniques used in practice to accomplish a discectomy. Options such as micro-discectomy, endoscopic discectomy, moreover the traditional laminectomy/ discectomy are available to the surgeon to accomplish decompression of a spinal nerve root. Even though all of the strategies described above are successful in resolving the initial herniation, there is still a risk of recurrent prolapse and potential instability [4]. The aim of our study is to find out how much iatrogenic spinal instability occurs after laminectomy, discectomy, or facetectomy in lumbar surgery, and factors affecting instability.

\section{Patients and Methods}

\section{Study population}

This is a prospective study of 50 cases of degenerative lumbar spondylosis complaining of various symptoms of claudication, sciatica, and back pain which were surgically managed by laminectomy 
according to the level of stenosis mesial facetectomy was added relative to the degree of stenosis if needed, Twenty-four patients needed discectomy in the period between October 2018 and October 2020 in the neurosurgery department at Cairo university hospitals.

\section{Inclusion criteria}

Patients with intractable low back pain associated with radiculopathy, failed conservative management, and patients were diagnosed as lumbar canal stenosis or lumbar disc herniation in Age group between 15 and 60 years and were fit for surgery.

\section{Exclusion criteria}

Back pain and radiculopathy caused by other etiologies (spinal tumors, spinal trauma, etc.).

\section{Data collection and outcomes}

Personal history including name, age, sex, symptomatology including back pain, lower limb pain, and claudication pain. Patients were evaluated for the presence or absence of motor deficit, sensory deficit, and cauda equina.

Pain was analyzed according to site, character, severity, distribution, and visual analog scale (VAS) and disability analyzed according to oswestry disability index (ODI).

Preoperative preparation including routine laboratory investigations and radiological investigations (Plain X-ray and magnetic resonance imaging (MRI) lumbosacral spine) were done.

\section{Operative management}

A low midline skin incision was done, dissection was done until vertebral fascia was exposed, a longitudinal fascial incision was done. Incision of supraspinous ligament then removal of the spinous process laminectomy either using Kerrison beginning from caudal to rostral direction. The ligamentum flavum is carefully dissected from the underlying dura. The nerve roots were decompressed by the removal of the ligamentum flavum and bone spur.

Mesial facetectomy was done for twenty-two patients to decompress the thecal sac and neural foramina. Twenty-fourpatients with sciatica and signs of disc herniation underwent discectomy.

\section{Follow up}

Patients were followed clinically and radiological immediately after surgery and after 2 years on an outpatient basis.

\section{Patients criteria}

In our study the patients were divided into two groups instability group and non-instability group being affected with some variables which were Age, sex, body mass index (BMI), number of levels operated upon, type of operation done either laminectomy only or being combined with conventional discectomy, mesial facetectomy done or not, VAS and ODI pre, postoperative and follow-up after 2 years.

\section{Statistical methods}

By the use of statistical package for the Social Sciences version 26 (IBM Corp., Armonk, NY, USA) the data has been coded and entered. In quantitative data, median, minimum, and maximum were used, while categorical data were summarized using frequency (count) and relative frequency (percentage). The nonparametric Mann-Whitney test was used to make comparisons between quantitative variables. The Chi-square $\left(\chi^{2}\right)$ test was used to compare categorical data. Exact test was used instead when the expected frequency is $<5$. $p<0.05$ were considered as statistically significant.

\section{Results}

\section{Patient demographics}

This study included fifty cases of degenerative lumbar spondylosis, 26 were female (52\%) and 24 were male $(48 \%)$ mean age was 50.12 years and the mean age of patients who developed postoperative instability was 44.44 years.

Table 1: Visual analog scale and oswestry disability index pre, postoperative and follow up after 2 years

\begin{tabular}{llllll}
\hline & Mean & SD & Median & Minimum & Maximum \\
\hline Age & 50.12 & 7.10 & 50.00 & 33.00 & 60.00 \\
VAS back pain Pre & 4.56 & 1.25 & 4.00 & 3.00 & 8.00 \\
VAS back pain immediate post & 2.12 & 0.63 & 2.00 & 1.00 & 3.00 \\
VAS back pain post 2 years & 2.22 & 1.85 & 1.00 & 1.00 & 7.00 \\
VAS leg pain pre & 6.98 & 1.32 & 7.00 & 4.00 & 9.00 \\
VAS leg pain immediate post & 2.14 & 0.67 & 2.00 & 1.00 & 3.00 \\
VAS leg pain post 2 years & 2.26 & 1.86 & 2.00 & 1.00 & 7.00 \\
ODI pre & 39.44 & 8.34 & 40.00 & 19.00 & 57.00 \\
ODI immediate post & 9.08 & 1.72 & 9.00 & 5.00 & 13.00 \\
ODI post 2 years & 13.28 & 13.11 & 8.00 & 5.00 & 51.00 \\
\hline VAS: Visual analog scale, ODI: Oswestry disability index. & & &
\end{tabular}

Eighteen patients (36\%) their BMI were $<25$ (Normal or underweight) and thirty-two patients (64\%) were $>25$ (overweight or obese), seven patients out of nine who developed postoperative instability $(77.7 \%)$ were $>25$ which was statistically significant $(p=0.032)$.

All 50 patients $(100 \%)$ presented with low back pain, 28 patients $(56 \%)$ presented with claudication, and 22 patients (44\%) presented with sciatica. 


\section{Factors affecting instability}

We found that nine patients (18\%) developed postoperative instability.

Twenty-eight patients (56\%) were operated upon by single-level laminectomy and twenty-two patients $(44 \%)$ were operated upon by multiple levels laminectomies. Eight patients out of nine $(88.9 \%)$ who developed postoperative instability were operated by multiple levels laminectomies showing significant results $(p=0.007)$ as shown in Figure 1 .

Table 2: Variables affecting postoperative instability (All values highlighted in yellow are significant $p$-values $(p<0.05)$

\begin{tabular}{|c|c|c|c|c|c|}
\hline & \multicolumn{4}{|c|}{ Post-Op Instability } & \multirow[t]{3}{*}{$p$-value } \\
\hline & \multicolumn{2}{|l|}{ Yes } & \multicolumn{2}{|l|}{ No } & \\
\hline & Count & $\begin{array}{l}\text { Column } \\
(\mathrm{n} \%)\end{array}$ & Count & $\begin{array}{l}\text { Column } \\
(\mathrm{n} \%)\end{array}$ & \\
\hline \multicolumn{6}{|l|}{ Sex } \\
\hline Female & 6 & 66.7 & 20 & 48.8 & \multirow[t]{2}{*}{0.467} \\
\hline Male & 3 & 33.3 & 21 & 51.2 & \\
\hline \multicolumn{6}{|l|}{ BMI } \\
\hline$<25$ & 2 & 22.2 & 16 & 48.8 & \multirow[t]{2}{*}{0.032} \\
\hline$>25$ & 7 & 77.7 & 25 & 39.0 & \\
\hline \multicolumn{6}{|l|}{ No of Levels } \\
\hline Single & 1 & 11.1 & 27 & 65.9 & \multirow[t]{2}{*}{0.007} \\
\hline Multiple & 8 & 88.9 & 14 & 34.1 & \\
\hline \multicolumn{6}{|l|}{ Methods } \\
\hline laminectomy & 5 & 55.6 & 21 & 51.2 & \multirow[t]{2}{*}{1} \\
\hline laminectomy+discectomy & 4 & 44.4 & 20 & 48.8 & \\
\hline \multicolumn{6}{|l|}{ Mesial facitectomy } \\
\hline Yes & 7 & 77.8 & 15 & 36.6 & \multirow[t]{2}{*}{0.032} \\
\hline No & 2 & 22.2 & 26 & 63.4 & \\
\hline \multicolumn{6}{|l|}{ Post op. Modic changes } \\
\hline Yes & 8 & 88.9 & 0 & 0 & \multirow[t]{2}{*}{0.007} \\
\hline No & 1 & 11.1 & 41 & 100 & \\
\hline
\end{tabular}

Twenty-six patients $(52 \%)$ were operated upon by conventional laminectomy only and twenty-four patients $(48 \%)$ were operated upon by laminectomy and discectomy. Five patients out of nine $(55.6 \%)$ who developed post-operative instability were operated upon by laminectomy only. Mesial facetectomy was done for twenty-two patients (44\%), Seven patients out of nine $(77.8 \%)$ developed post-operative instability showing significant results $(p=0.032)$ as illustrated in Bar chart in Figure 2.

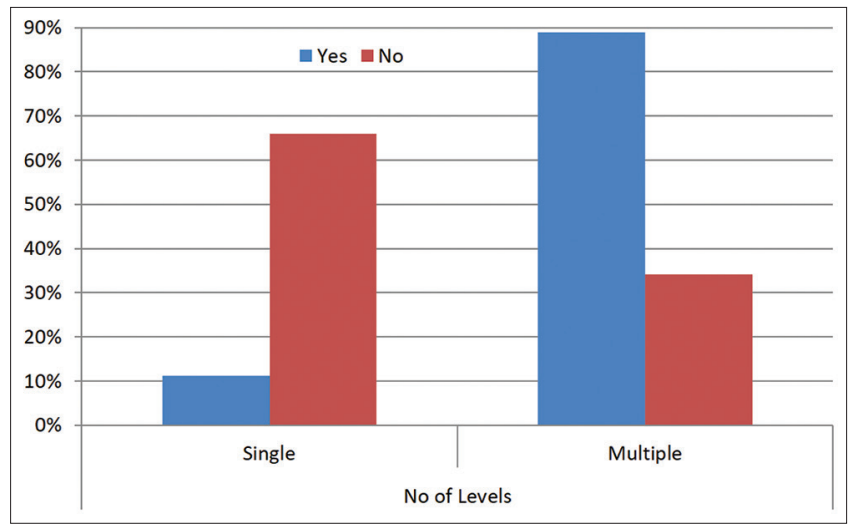

Figure 1: Showing the relation between no. of levels operated upon and postoperative instability

In patients having postoperative instability, the VAS back pain, leg pain, and ODI increased significantly after 2 years from the operation in comparison to immediate postoperative when being compared to patients who did no't develop postoperative instability. VAS and ODI Pre, postoperative and follow up after 2 years are summarized in Table 1.

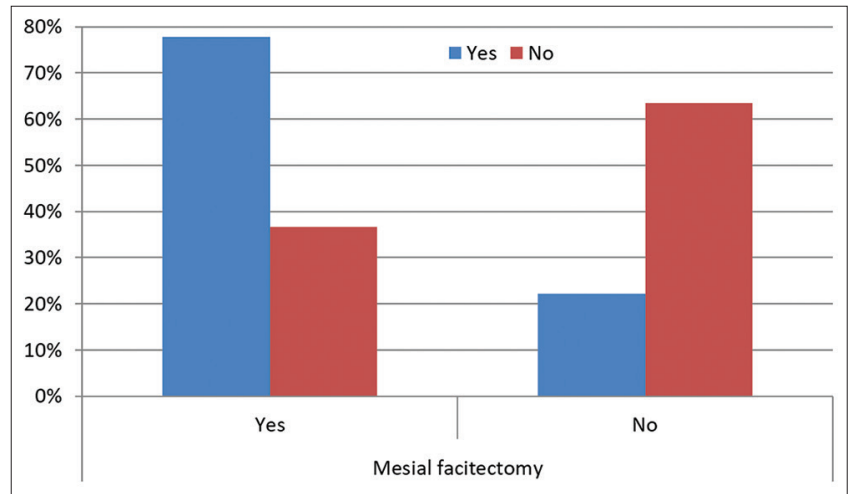

Figure 2: Bar chart showing the relation between mesial facetectomy and postoperative instability

Modic changes were present in the follow-up MRI after 2 years in eight patients (88.9\%) of the instability group and only one patient $(11.1 \%)$ in the instability group did not show Modic changes in his follow-up MRI which was statistically significant $(p=0.007)$. Variables affecting postoperative instability are summarized in Table 2.

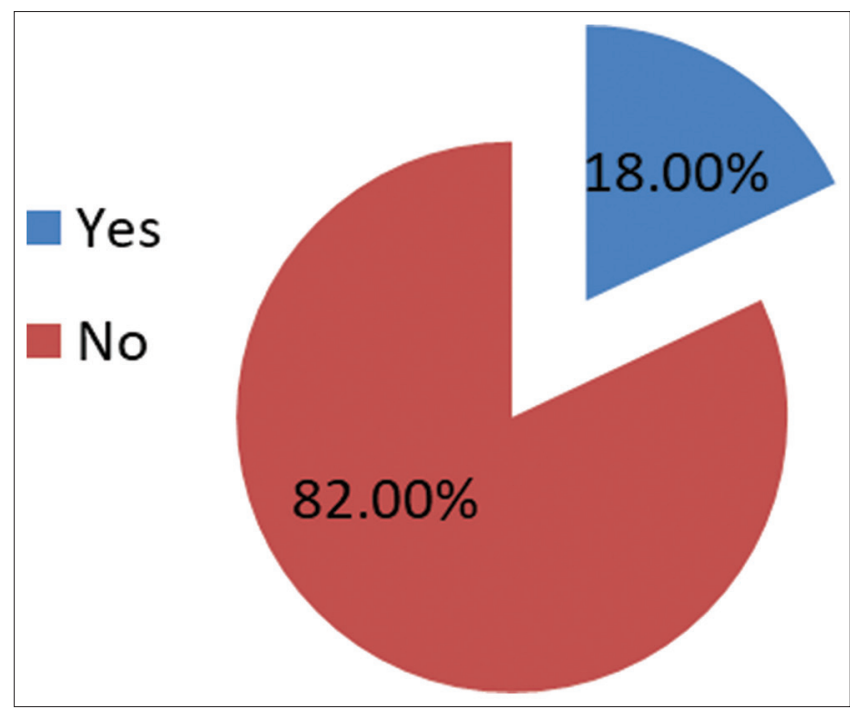

Figure 3: Pie chart showing the incidence of postoperative instability

\section{Discussion}

Spinal stability is accomplished by dynamic interaction of many structural systems in the body. When iatrogenic instability occurs, this may present as axial low back pain or radicular pain.

Decompressing the central canal and lateral recesses surgically improves common stenotic symptoms such as neurogenic claudication and radiculopathy. However, in a few patients, open laminectomy may affect the spinal integrity leading to iatrogenic instability [5].

This iatrogenic instability significantly impacts clinical outcomes and increases the risk for revision 
surgery [6]. The microdiscectomy method produces less tissue damage than conventional open discectomy and, thus, leads to less epidural fibrosis, postoperative back pain, radicular pain, and segmental instability [7].

Critics of minimally invasive surgery techniques note the possibility of inadequate decompression with some of these procedures [8].

In our study, fifty patients were operated upon by either conventional decompressive laminectomy or combined with discectomy. Nine patients (18\%) developed postoperative spinal instability as illustrated in Pie chart in Figure 3.

According to Guha et al. there was a higher incidence of reoperation among patients with preexisting spondylolisthesis $(8.9 \%)$ versus stenosis alone $(1.1 \%)$ and among patients in whom open decompression was performed $(11 \%)$ in comparison to a minimally invasive decompression (0.7\%) [9]. In a study of 105 patients who had laminectomies across 1-4 levels for degenerative lumbar disease, ten patients $(9.5 \%)$ developed iatrogenic instability at the same operative levels, according to Ramhmdani et al. [10], while 42 patients underwent single-level decompressive laminectomy without fusion and discectomy for the first time, according to Yang et al. Spinal instability occurred in 15 patienSts $(35.7 \%)$ [11].

Factors being discussed affecting postsurgical lumbar spinal stability include age, sex, BMI, the surgical method either conventional laminectomy only or was combined with conventional discectomy, mesial facetectomy was done or not, and number of levels operated upon.

Our study included 26 female patients (52\%) and 24 male patients (48\%), mean age was 50.12 years and the mean age of patients who developed postoperative instability was 44.44 years, unlike Shenkin and Hash who described series of 59 patients treated by multiple-level bilateral laminectomies and facetectomies, the average age was 56.8 years [12]., also Yang et al. discussed Spinal instability occurred in 15 patients (35.7\%). Twelve patients were men and 3 patients were women. Spinal instability occurred more often in patients aged $>65$ years $(40.9 \%$ vs. $30.0 \%)$ [11].

This difference compared to our study which shows decrease in the mean age of patients who developed postoperative instability may be explained by the return of patients to the usual daily activities and work and carrying heavy objects after surgery.

We reported 18 patients (36\%) their BMI was $<25$ (Normal or underweight) and 32 patients (64\%) was more than 25 (overweight or obese), out of nine patients who developed postoperative instability seven patient $(77.7 \%)$ had $\mathrm{BMI}>25$, and the other two patients had BMI $<25$, and this indicates that the BMI was prognostically related to postoperative instability, in contrary to Yang et al. who described 20 Patients $(47.6 \%)$ with obesity $(\mathrm{BMI}>25)$ and 22 patients $(52.3 \%)$ their body mass index was $<25$, out of 15 patients who developed postoperative instability seven patients (46.6\%) had BMI more than 25 [11].

We operated 26 patients upon by conventional laminectomy only, and 24 patients were operated by laminectomy and discectomy. Out of nine patients who developed postoperative instability five patients (55.5\%) were operated upon by laminectomy only, and the other four patients were operated upon by laminectomy and discectomy, This was similar to Yang et al. finding that there was no statistically significant difference between partial and complete laminectomy [11].

Abumi et al. using biomechanical model found that removing the medial facet capsules (approximately one third to one half of a facet joint) destabilizes the spine by significantly increasing spinal flexion by nearly twelve degrees [13], this is in line with our findings, in which mesial facetectomy was performed on 22 patients, with mesial facetectomy performed on seven of the nine patients who developed postoperative instability $(77.7 \%)$, in contrast, Fox et al. reported that 124 patients with degenerative lumbar stenosis underwent decompression surgery, 39 patients $(31.4 \%)$ developed listhesis after being operated upon by laminectomies and bilateral medial facetectomies [14].

Also Ramhmdani et al. discussed 10 patients who developed postoperative iatrogenic spondylolisthesis, all 3 patients with medial facetectomies had disrupted facet joints at the level of the subsequent spondylolisthesis. In addition, 24 of 95 (25.3\%) of patients without iatrogenic spondylolisthesis had a facet joint affected after decompression, while 3 of 10 (30\%) of patients who acquired spondylolisthesis had facet joints affected [10].

Out of nine patients who developed spinal instability eight patients $(88.8 \%)$ were operated upon by multiple level laminectomy showing significant statistics, this was opposing to Shenkin and Hash study which found that decompressing $>3$ levels increases the chance of postoperative listhesis to $15 \%$ compared with $10 \%$ in 2-level and 6\% in 1-level laminectomy [12].

Also, Fox et al. found $59 \%$ developed postoperative anterolisthesis after decompressing 3 levels, $53 \%$ after laminectomy for 2 levels, and $13 \%$ after 1 level. Removal of more structural components during lumbar surgery increases the risk of postoperative instability.

Modic changes have been found presenting in the follow-up MRI after 2 years in eight patients $(88.9 \%)$ of the instability group and only one patient $(11.1 \%)$ in the instability group did not show Modic changes in his follow up MRI, hence the importance of Modic changes to be evaluated. Rahme et al. described Modic changes in 41 patients after lumbar discectomy. At the time of follow-up, twenty-six patients $(63.4 \%)$ developed Type 2 changes at the operated level, whereas only six patients $(14.6 \%)$ had 
Type 1 changes and nine patients (22\%) had normalappearing vertebral endplates [15].

\section{Conclusion}

In patients without pre-existing instability, wide laminectomy and extensive facetectomy for lumbar stenosis can lead to iatrogenic instability. BMI is a significant determinant of postoperative instability; a high BMI raises the risk of developing postoperative instability. The number of decompressed levels and the degree of decompression determine the probability of postoperative instability. Postoperative modic changes are important to be evaluated as they are indicator for developing postoperative instability. After lumbar surgery, recurrent radiculopathy should be closely evaluated for the risk of iatrogenic instability.

\section{References}

1. Panjabi The stabilizing system of the spine. Part I. Function, dysfunction, adaptation, and enhancement. J Spinal Disord. 1992;5(4):383-9; discussion 397. https://doi. org/10.1097/00002517-199212000-00001 PMid:1490034

2. Lai PL, Chen LH, Niu CC, Fu TS, Chen WJ. Relation between laminectomy and development of adjacent segment instability after lumbar fusion with pedicle fixation. Spine. 2004;29(22):2527-32; discussion 2532. https://doi. org/10.1097/01.brs.0000144408.02918.20 PMid: 15543067

3. Gillet $P$. The fate of the adjacent motion segments after lumbar fusion. J Spinal Disord Tech. 2003;16(4):338-45. https://doi. org/10.1097/00024720-200308000-00005 PMid:12902949

4. Carragee EJ, Han MY, Suen PW. Clinical outcomes after lumbar discectomy for sciatica: the effects of fragment type and anular competence. J Bone Joint Surg Am. 2003;85(1):102-8. https:// doi.org/10.2106/00004623-200301000-00016 PMid:12533579

5. Resnick D, Choudhri T, Dailey A, Groff MW, Khoo L, Matz PG, et al. Guidelines for the performance of fusion procedures for degenerative disease of the lumbar spine. Part 10: Fusion following decompression in patients with stenosis without spondylolisthesis. J Neurosurg Spine. 2005;2(6):686-91. https:// doi.org/10.3171/spi.2005.2.6.0686

PMid:16028738
6. Adogwa O, Parker S, Shau D, Mendenhall SK, Aaronson O, Cheng JS, et al. Cost per qualityadjustedlife year gained of revision neural decompression and instrumented fusion for same-level recurrent lumbar stenosis: Defining the value of surgical intervention. J Neurosurg Spine. 2012;16(2):135-40. https://doi.org/10.3171/2011.9.spine11308

PMid:2054639

7. Wenger M, Mariani L, Kalbarczyk A, Gröger U. Long-term outcome of 104 patients after lumbar sequestrectomy according to Williams. Neurosurgery 2001;49(2):329-34; discussion 3345. https://doi.org/10.1227/00006123-200108000-00013 PMid: 11504108

8. Wong A, Smith Z, Lall R, Bresnahan LE, Fessler RG. The microendoscopic decompression of lumbar stenosis: A review of the current literature and clinical results. Minim Invasive Surg. 2012;2012:325095. https://doi.org/10.1155/2012/325095 PMid:22900163

9. Guha D, Heary R, Shamji M. latrogenic spondylolisthesis following laminectomy for degenerative lumbar stenosis: Systematic review and current concepts. Neurosurg Focus 2015;39(4):E9. https://doi.org/10.3171/2015.7.focus15259 PMid:26424349

10. Ramhmdani S, Xia $\mathrm{Y}, \mathrm{Xu} \mathrm{R}$, Kosztowski T, Sciubba $\mathrm{D}$, Witham $\mathrm{T}$, et al. latrogenic spondylolisthesis following open lumbar laminectomy: Case series and review of the literature. World Neurosurg. 2018;113:e383-90. https://doi.org/10.1016/j. wneu.2018.02.039 PMid:29454126

11. Yang J, Kim S, Kim T, Park KH. Analysis of factors contributing to postoperative spinal instability after lumbar decompression for spinal stenosis. Korean J Spine. 2013;10(3):149-54. https:// doi.org/10.14245/kjs.2013.10.3.149

PMid:24757477

12. Shenkin H, Hash C. Spondylolisthesis after multiple bilatera laminectomies and facetectomies for lumbar spondylosis. J Neurosurg. 1979;50(1):45-7. https://doi.org/10.3171/ jns.1979.50.1.0045 PMid: 758378

13. Abumi K, Panjabi M, Kramer K, Duranceau J, Oxland T, Crisco JJ, et al. Biomechanical evaluation of lumbar spinal stability after graded facetectomies. Spine (Phila Pa 1976). 1990;15(11):11427. https://doi.org/10.1097/00007632-199011010-00011 PMid:2267608

14. Fox M, Onofrio B, Hanssen A. Clinical outcomes and radiological instability following decompressive lumbar laminectomy for degenerative spinal stenosis: A comparison of patients undergoing concomitant arthrodesis versus decompression alone. J Neurosurg. 1996;85(5):793-802. https://doi. org/10.3171/jns.1996.85.5.0793

PMid:8893716

15. Rahme R, Moussa R, Bou-Nassif R, Maarrawi J, Rizk T, Nohra G, et al. What happens to Modic changes following lumbar discectomy? Analysis of a cohort of 41 patients with a 3-to 5-year follow-up period. J Neurosurg Spine. 2010;13(5):562-7. https://doi.org/10.3171/2010.5.spine09818

PMid:21039144 